\title{
Multiparameter approach to evaluate elderly patients undergoing aortic valve replacement
}

\author{
Michele Gallo, MD, and Gino Gerosa, MD
}

The aging population is increasing, and as a result there are a growing number of elderly patients presenting with senile degenerative calcific aortic stenosis. Advanced age alone cannot be considered a precluding factor for surgery. Medical treatment options are limited. Elderly patients who did not receive aortic valve replacement (AVR) presented a 12-fold increased mortality risk compared with surgically treated patients. ${ }^{1}$ Isolated AVR in octogenarians can be performed with a low overall pooled postoperative mortality of $6.7 \% .^{2}$ AVR in elderly patients results in significant healthrelated quality of life with improvement in cardiac symptoms and significant functional gains after surgery. ${ }^{3}$ Furthermore, econometric analysis has shown that AVR is cost-effective even for very elderly patients. ${ }^{4}$

Surgical decision-making in this selected population undergoing cardiac surgery is challenging because of the heterogeneity of comorbidity, disability/frailty, and life expectancy. Transcatheter aortic valve replacement (TAVR) and sutureless AVR are emerging alternatives to conventional surgery in selected high-risk surgical cases or inoperable patients. ${ }^{5}$ In regard to current decisionmaking for AVR, the difficulty is to translate from the risk score to the best surgical treatment possibilities tailored to the individual patient. The actual risk scores do not completely describe the elderly population. There is a demand to combine (1) cardiac surgery risk scores with (2) measures of frailty and disability, and (3) life expectancy to provide a more complete model for risk prediction.

(1) In cardiac surgery, the European System for Cardiac Operative Risk Evaluation (euroSCORE) II, Society of Thoracic Surgeons (STS) score, and Parsonnet score are used the most. Their aim is to assess mortality and morbidity after cardiac surgery considering comorbidity and preoperative risk factors. The euroSCORE II and STS score have moderate discrimination for predicting 30-day mortality after TAVR. ${ }^{6}$ Moreover, these scores do not stratify the grade of aortic stenosis severity, based on left

\footnotetext{
From the Division of Cardiac Surgery, Department of Cardiac, Thoracic and Vascular Sciences, University of Padua, Padova, Italy.

Disclosures: Dr Gerosa reports consulting fees from Astra Zeneca. The other author has nothing to disclose with regard to commercial support.

Received for publication Dec 13, 2013; revisions received March 19, 2014; accepted for publication March 27, 2014; available ahead of print April 27, 2014.

Address for reprints: Gino Gerosa, MD, Division of Cardiac Surgery, Department of Cardiac, Thoracic and Vascular Sciences, Via Giustiniani 2, 35128 Padova, Italy

(E-mail: gino.gerosa@unipd.it).

J Thorac Cardiovasc Surg 2014;148:1749-51

$0022-5223 / \$ 36.00$

Copyright (c) 2014 by The American Association for Thoracic Surgery

http://dx.doi.org/10.1016/j.jtcvs.2014.03.051
}

ventricle stroke volume (normal flow vs low flow), pressure gradient level (low gradient vs high gradient), and ejection fraction (normal vs reduced).

(2) Frailty is defined as a geriatric syndrome of impaired resiliency to stressors (eg, cardiac surgery) and can quantified by the 5-m gait speed, 5-item Cardiovascular Health Study frailty scale, 7-item expanded Cardiovascular Health Study frailty scale, and 4-item MacArthur Study of Successful Aging frailty scale subdimensions. Disability is defined as the impaired ability to carry out functional tasks and can evaluated by the 6-item Katz Activities of Daily Living scale, 7-item Older Americans Research and Services Instrumental Activities of Daily Living scale, and 7-item Nagi scale. ${ }^{7}$ Moreover, frailty and disability can assessed in a single score: the Comprehensive Assessment of Frailty or its simplified form, Frailty predicts One year after Elective Cardiac Surgery Test. ${ }^{8}$ The goal of frailty and disability scores is to assess mortality and morbidity for the short- and long-term after cardiac surgery in elderly patients. To evaluate short-term post-hospital mortality in the elderly, there are specific indexes, such as the Multidimensional Prognostic Index, which evaluates for hospitalized 1-year mortality on admission, ${ }^{9}$ and a Prognostic Index by Walter and colleagues, ${ }^{10}$ which evaluates for hospitalized 1-year mortality on discharge.

(3) Life expectancy is the average number of years of life remaining for people who have attained a given age. It is plotted in specific tables of life calculated as a snapshot of age-specific mortality rates in the recent past. ${ }^{11}$ Prediction of life expectancy could be less accurate in the elderly population for high heterogeneity of associated conditions. Thus, to be able to predict life expectancy accurately in the elderly, numerous long-term mortality prognostic indices ${ }^{12}$ have been developed at different time frames in hospitalized patients. The Dramé Index can quantify frailty and disability scores and identify predictive factors for 2-year mortality in frail elderly patients after hospitalization. ${ }^{13}$

We propose that in elderly patients undergoing cardiac surgery, the real global score has to be assessed considering life expectancy (evaluated as long-term mortality) and short-term mortality associated with comorbidity.

We consider high short-term mortality/high morbidity to be an STS score greater than 10\%. A logistic euroSCORE greater than $20 \%$ has been suggested as an indication for TAVR, but this is known to markedly overestimate operative mortality, ${ }^{14}$ and a cutoff for euroSCORE II is still under evaluation. ${ }^{6}$ A Prognostic Index greater than 6 by Walter and colleagues ${ }^{10}$ presented a risk of 1 -year mortality of 


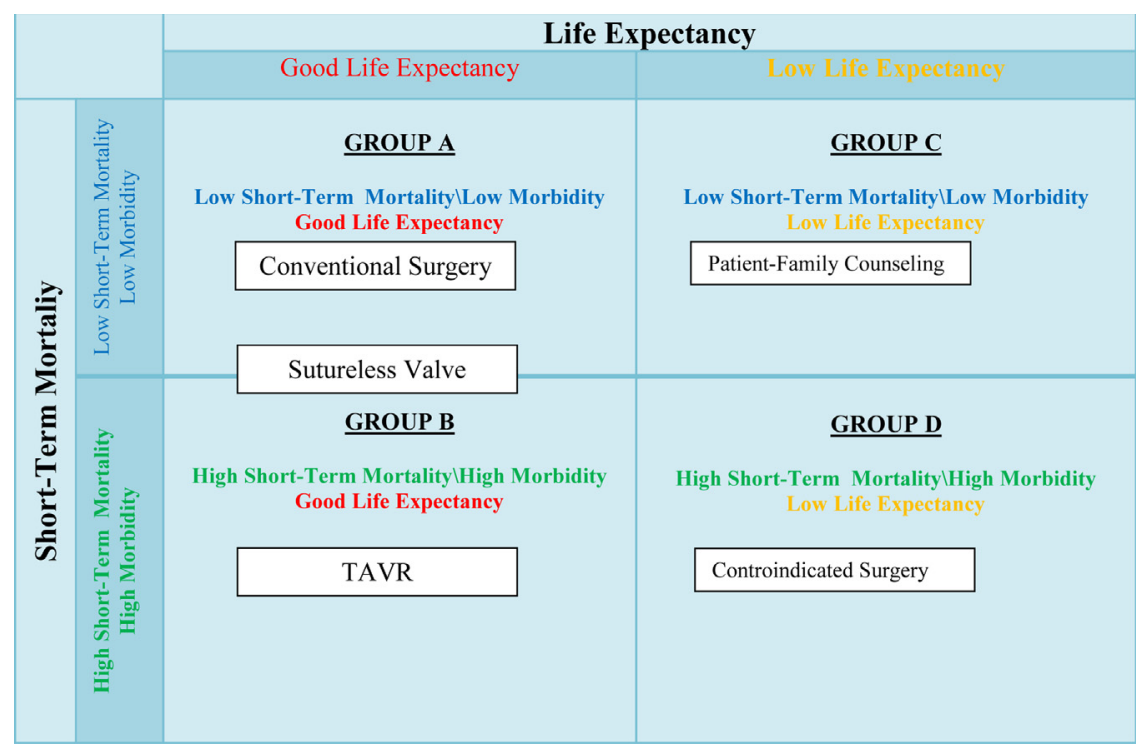

FIGURE 1. Multiparameter approach to evaluate elderly patients undergoing cardiac surgery. TAVR, Transcatheter aortic valve replacement.

64\% (95\% confidence interval [CI], 58-70), and a Multidimensional Prognostic Index ${ }^{9}$ value between 0.67 and 1.0 presented a risk of- 1 year mortality of $45 \%(95 \%$ CI, 47 $65)$. These 2 indices could properly select an elderly frail population with disability associated with high short-term mortality/high morbidity for AVR.

We consider a short life expectancy (evaluated as longterm mortality) to be less than 1 year. European guidelines indicate eligible patients for TAVR to have a life expectancy of more than 1 year. ${ }^{14}$ A Dramé Index ${ }^{13}$ value greater than 6 presented a risk of 2-year mortality of $65 \%$ (95\% CI, 5576) and can properly select an elderly frail population with disability associated with short life expectancy.

We classified the elderly patients undergoing cardiac surgery in 4 risk groups (Figure 1): From group A to group D, there is an increasing risk score.

Group A is characterized by low short-term mortality/ low morbidity and a good life expectancy. For these patients, conventional cardiac surgery is usually the suggested solution. Group B presents elderly patients with a high short-term mortality and high morbidity score, but good life expectancy. TAVR is usually advised in this group, whereas sutureless AVR is usually considered as a solution for the intermediate group between A and B.

Patients in group $\mathrm{C}$ present low short-term mortality/low morbidity and low life expectancy. A standard surgical procedure is achievable; however, it is important to consider that elderly patients with a low life expectancy require a lengthy recovery period, so counseling sessions with the patients and their family or caregivers are essential. In group D patients with high short-term mortality/high morbidity and low life expectancy, conventional surgery and TAVR would be against the patient's best interest, and medical therapy is probably advisable.

A multiparameter approach to evaluate elderly patients undergoing cardiac surgery requires a dedicated "heart team," especially for patients in groups B, C, and D. The clinical impact of decision-making using a multiparameter approach could be a cost-effective strategy to improve treatment outcomes, quality of life, and resource optimization.

\section{References}

1. Kojodjojo P, Gohil N, Barker D, Youssefi P, Salukhe TV, Choong A, et al. Outcomes of elderly patients aged 80 and over with symptomatic, severe aortic stenosis: impact of patient's choice of refusing aortic valve replacement on survival. QJM. 2008;101:567-73.

2. Vasques F, Messori A, Lucenteforte E, Biancari F. Immediate and late out come of patients aged 80 years and older undergoing isolated aortic valve replacement: a systematic review and meta-analysis of 48 studies. Am Heart J. 2012;163: 477-85.

3. Shan L, Saxena A, McMahon R, Wilson A, Newcomb A. A systematic review on the quality of life benefits after aortic valve replacement in the elderly. $J$ Thorac Cardiovasc Surg. 2013;145:1173-89.

4. Wu Y, Jin R, Gao G, Grunkemeier GL, Starr A. Cost-effectiveness of aortic valve replacement in the elderly: an introductory study. J Thorac Cardiovasc Surg. 2007; 133:608-13.

5. D’Onofrio A, Rizzoli G, Messina A, Alfieri O, Lorusso R, Salizzoni S, et al. Conventional surgery, sutureless valves, and transapical aortic valve replacement: what is the best option for patients with aortic valve stenosis? A multicenter, propensity-matched analysis. J Thorac Cardiovasc Surg. 2013;146:1065-70.

6. Durand E, Borz B, Godin M, Tron C, Litzler PY, Bessou JP, et al. Performance analysis of EuroSCORE II compared to the original logistic EuroSCORE and STS scores for predicting 30-day mortality after transcatheter aortic valve replacement. Am J Cardiol. 2013;111:891-7.

7. Afilalo J, Mottillo, Eisenberg MJ, Alexander KP, Noiseux N, Perrault LP, et al. Patients at high risk of mortality or major morbidity addition of frailty and disability to cardiac surgery risk scores identifies elderly. Circ Cardiovasc Qual Outcomes. 2012;5:222-8.

8. Sündermann S, Dademasch A, Rastan A, Praetorius J, Rodriguez H, Walther T, et al. One-year follow-up of patients undergoing elective cardiac surgery 
assessed with the Comprehensive Assessment of Frailty test and its simplified form. Interact Cardiovasc Thorac Surg. 2011;13:119-23.

9. Pilotto A, Ferrucci L, Franceschi M, D’Ambrosio LP, Scarcelli C, Cascavilla L, et al. Development and validation of a multidimensional prognostic index for one-year mortality from comprehensive geriatric assessment in hospitalized older patients. Rejuvenation Res. 2008;11:151-61.

10. Walter LC, Brand RJ, Counsell SR, Palmer RM, Landefeld CS, Fortinsky RH, et al. Development and validation of a prognostic index for 1-year mortality in older adults after hospitalization. JAMA. 2001;285:2987-94.

11. United States Life Tables, 2008. NVSR Volume 61, Number 3. 63 pp. (PHS) 2012-1120.
12. Yourman LC, Lee SJ, Schonberg MA, Widera EW, Smith AK. Prognostic indices for older adults: a systematic review. JAMA. 2012;307:182-92.

13. Dramé M, Novella JL, Lang PO, Somme D, Jovenin N, Lanièce I, et al. Derivation and validation of a mortality-risk index from a cohort of frail elderly patients hospitalised in medical wards via emergencies: the SAFES study. Eur J Epidemiol. 2008;23:783-91.

14. Vahanian A, Alfieri O, Andreotti F, Antunes MJ, Barón-Esquivias G, Baumgartner H, et al. Guidelines on the management of valvular heart disease (version 2012): the Joint Task Force on the Management of Valvular Heart Disease of the European Society of Cardiology (ESC) and the European Association for Cardio-Thoracic Surgery (EACTS). Eur J Cardiothorac Surg. 2012;42:S1-44. 